\title{
A Psychometric Comparison of the Internet Addiction Test, the Internet-Related Problem Scale, and Self-Diagnosis
}

\author{
Laura Widyanto, Ph.D., Mark D. Griffiths, Ph.D., and Vivienne Brunsden, B.Sc.
}

\begin{abstract}
One of the more prominent issues in the field of Internet addiction is the validity of the instrument used to assess users' level of Internet involvement. Many of the instruments used to assess Internet addiction have high face validity but have yet to be tested psychometrically. The aim of this study is to compare two of the most used Internet addiction research measures, the Internet Addiction Test (IAT) and the Internet-Related Problem Scale (IRPS), along with a self-diagnostic question simply asking Internet users if they thought they were addicted to the Internet. A total of 225 Internet users participated in the study (69 males and 156 females). Participants who defined themselves as Internet addicts had higher scores on both the IAT and IRPS, and the three different Internet addiction measures were strongly correlated to each other. For the IAT, factor analysis generated three factors (emotional/psychological conflict; time management issues; mood modification) explaining $56.3 \%$ of the variance. For the IRPS, factor analysis generated four factors (negative effects of Internet use; mood modification; loss of control; increased Internet use) explaining $60.2 \%$ of the variance. The implications for these findings are discussed.
\end{abstract}

\section{Introduction}

O NE OF THE MORE PROMINENT ISSUES in the field of Internet addiction is the validity of the instrument used to assess users' level of Internet involvement. The instruments used vary widely from study to study, and are a likely contributor to the differences in findings. Some of the instruments are more suitable for clinical diagnosis rather than research, ${ }^{1-4}$ whereas others are more psychometrically based. ${ }^{5-8}$ Previous studies have explored the psychometric properties of available instruments to measure Internet addiction-particularly the Internet Addiction Test (IAT) ${ }^{9}$ and the Internet-Related Problem Scale (IRPS).$^{10}$ These instruments appear to show high face validity, as they both seem to be assessing some of the core components of addiction.

The IAT $^{9}$ was designed by Kimberly Young to assess which areas of an individual's life might be affected by their excessive Internet use. The diagnostic questionnaire comprised eight items that had been modified from the DSM-IV criteria for pathological gambling along with 12 new items. Young suggested a cut-off score of five, the same as the number of criteria used to diagnose pathological gambling. However, Beard and Wolf ${ }^{3}$ raised a few concerns with these criteria. First, they questioned the objectivity and how much of it was based on self-report. Some of the criteria can be easily reported or denied by a participant, and their judgment might be impaired, thus influencing the accuracy of the diagnosis. Second, some of the items were deemed to be too vague, and they asserted that some of the terminology needed to be clarified (e.g., what is meant by "preoccupation"?). Third, they questioned whether the criteria for pathological gambling were the most accurate to use as a basis for identifying Internet addiction. Despite Beard and Wolf's criticisms, it should be noted that the IAT was the first instrument to assess Internet addiction to be developed (so was used in the absence of any other measures) and is still used by some researchers in contemporary studies. ${ }^{11,12}$

The IRPS developed by Armstrong et al. ${ }^{10}$ is a 20 -item scale comprising questions relating to tolerance, craving, and negative impacts of Internet use. The IRPS was found to have a moderate level of internal consistency, suggesting that the items were homogenous and related to the construct of Internet addiction. It was also found to be significantly correlated to the number of hours spent online and the MMPI-2 Addiction Potential Scale, supporting the construct validity of the IRPS. Petrie and Gunn ${ }^{13}$ employed a different approach when examining the relationship between Internet addiction, sex, age, depression, and introversion. They simply asked their 445 participants whether they thought themselves to be addicted to the Internet. Using this one question, they reported that nearly half $(46 \%)$ claimed that they were "addicted" to the Internet.

International Gaming Research Unit, Psychology Division, Nottingham Trent University, Nottingham, United Kingdom. 
Many of the instruments used to assess Internet addiction have high face validity but have yet to be tested psychometrically. The aim of this study is to compare two of the most used Internet addiction research measures, the IAT and the IRPS. These were selected because of their suitability for online research, their clear phrasing of the questions, and their relatively short length (20 items each). This study also explored if there was an association between the scores of these questionnaires and Petrie and Gunn's ${ }^{11}$ simple selfdiagnostic question, to see how participants' judgment of their own involvement with the Internet relate to their actual scores on the two Internet addiction measures.

\section{Method}

\section{Participants}

A total of 225 Internet users participated in the study, comprising 69 males (31\%) and 156 females (69\%). The participants' ages ranged from 16 to 66 years $(M=25.2 ; S D=9.6$ years). The mean age was 28 years for males ( $S D=12.6$ years) and 24 years for females $(S D=7.7$ years). Female participants were significantly younger than male participants $(t=2.79$, $d f=218 ; p<0.01)$

\section{Materials}

The questionnaire comprised 47 questions in total. More specifically, the questionnaire examined the following:

Demographic information. Questions 1 to 6 asked about participants' Internet usage and demographic information such as age, gender, how long they had been using the Internet, their approximate use of the Internet per day, and which Internet application they used most for personal purposes.

Internet Addiction Test. Questions 7 to 26 comprised the 20-item IAT. ${ }^{9}$ This was based on the DSM-IV criteria for pathological gambling. Respondents are asked to rate items on a 5-point Likert scale, covering the degree to which their Internet use affects their daily routine, social life, productivity, sleeping pattern, and feelings. The minimum score is 20 and the maximum is 100 . The higher the score, the greater the problems that the Internet causes. Young suggested that a score ranging from 20 to 39 is a typical online user who has no problems with their Internet usage. A score ranging from 40 to 69 signifies frequent problems due to Internet usage. Finally, a score ranging from 70 to 100 signifies that the Internet is causing significant problems for the user.

Internet-Related Problem Scale. Questions 27 to 46 comprised the 20-item IRPS questionnaire. ${ }^{10}$ The IRPS comprises 20 questions based on the adapted DSM-IV criteria for substance abuse, and includes questions relating to tolerance, withdrawal, craving, and negative life consequences. Also included from the DSM-IV criteria were loss of control, reduction of activity, and time spent on Internet-related activities. The questions are scored using a 10-point Likert scale, where $1=$ "not true at all" and $10=$ "extremely true." The IRPS was chosen because it has shown a moderate level of internal reliability (Cronbach's $\alpha=0.88$ ). This suggests that the items are homogenous.
Self-diagnostic question. Question 47 simply asked the participants whether they would define themselves as an "Internet addict."

\section{Procedure}

The questionnaire was compiled and distributed online via Autoform, a web-based questionnaire software facility developed at Nottingham Trent University. The sample for this study was recruited via a database created from a previous study that had asked whether they would be willing to participate in future research studies by the research team. Ethics approval was granted by the university's Ethics Committee. Over a 10-day period, e-mails were sent to participants in the research team's database. A link to the site of the questionnaire was provided, along with a brief explanation of the study. Once participants were transferred to the site of the questionnaire, they were able to read the instructions and complete the survey in their own time. Once participants submitted their responses, Autoform stored the data on the university's server. The data file could be opened in Excel, and was exported into SPSS (V15; SPSS, Inc., Chicago, IL) for analysis. Scores for each variable were checked to ensure that there were no errors made when transferring survey responses into the database.

\section{Results}

\section{Duration and frequency of Internet use}

The mean duration of Internet use among the participants was 6 years $(S D=2.5$ years). The mean duration of Internet use by males ( $M=6.8$ years; $S D=2.8$ years) was higher than that of females $(M=5.6$ years; $S D=2.3$ years $)$, a finding that was significant $(t=2.95, d f=109.51 ; p<0.01)$. There was no significant difference between males and females frequency of daily Internet use for personal purposes. The mean frequency of daily Internet use for personal use was 3.1 hours for males $(S D=3.6$ hours) and 2.2 hours for females $(S D=1.9$ hours).

\section{Correlations between variables}

In order to explore relationships between age, duration of use, frequency of use, total IAT scores, total IRPS scores, and the self-diagnostic question, correlations were calculated (see Table 1). Age was correlated with duration of use $(r=0.23$; $p<0.01)$ and frequency of use $(r=0.18 ; p<0.05)$. Duration of use was correlated with frequency of use $(r=0.22 ; p<0.01)$. Other variables that were correlated with frequency of use were total IAT score $(r=0.20 ; p<0.05)$ and total IRPS score $(r=0.22 ; p<0.01)$.

\section{Gender differences}

In males, a significant correlation was found between age and duration of Internet use $(r=0.30 ; p<0.01)$ but not among females. In females, significant correlations were found in relation to frequency of Internet use with total IAT scores $(r=0.33 ; p<0.01)$ and IRPS scores $(r=0.37 ; p<0.01)$ but not in males. The correlations between the three different Internet addiction measures were all significant in both male and females (see Table 2). Males reported higher IAT scores $(M=42.2 ; S D=15.0)$ than females $(M=35.6 ; S D=11.8)$, a finding that was significant $(t=3.54, d f=223 ; p<0.01)$. Males also reported higher IRPS scores $(M=68.0, S D=30.9)$ than 
Table 1. Correlations Between Age, Duration of Internet Use, Frequency of Internet Use, Total Internet Addiction Test Scores, Total Internet-Related Problem Scale Scores, AND the Self-Diagnostic Question $(N=225)$

\begin{tabular}{lcccccc}
\hline & Age & $\begin{array}{c}\text { Duration } \\
\text { of Internet use }\end{array}$ & $\begin{array}{c}\text { Frequency } \\
\text { of Internet use }\end{array}$ & $\begin{array}{c}\text { IAT } \\
\text { scores }\end{array}$ & $\begin{array}{c}\text { IRPS } \\
\text { scores }\end{array}$ & $\begin{array}{c}\text { Self-diagnostic } \\
\text { question }\end{array}$ \\
\hline Age & 1 & & & & & \\
Duration of Internet use & $0.23^{* *}$ & 1 & & & & \\
Frequency of Internet use & $0.18^{*}$ & $0.22^{* *}$ & 1 & & & \\
IAT scores & -0.1 & 0.03 & $0.20^{*}$ & 1 & & \\
IRPS scores & -0.13 & 0.04 & $0.22^{* *}$ & $0.90^{* *}$ & 1 & 1 \\
Self-diagnostic question & -0.08 & 0.11 & $0.20^{*}$ & $0.40^{* *}$ & $0.40^{* *}$ & 1 \\
\hline
\end{tabular}

${ }^{*}$ Correlation is significant at the 0.05 level; ${ }^{* *}$ correlation is significant at the 0.01 level.

females $(M=55.9, S D=26.1)$, a finding that was also significant $(t=2.85, d f=112.84 ; p<0.01)$.

\section{Applications most used}

Participants were asked which application of the Internet they used most often. For analysis purposes, the applications were categorized into 10 different types: e-mail, forums, surfing the web, specific information search, work-related, online gaming, auctioning and shopping, file transfers, chatting, and others (e.g., banking, pornography). The top three most commonly used Internet applications (accounting for $79 \%$ of the participants) were those for web browsing ( $29 \%$ of participants), e-mailing (29\%), and chatting (21\%). The remaining results are summarized in Table 3.

When the mean of demographic factors and total IAT and IRPS scores were compared across different types of application (see Table 3), the results showed wide variation. The highest mean IAT score was for forum Internet use and the lowest was for work-related Internet use. For IRPS, the highest was for file-transfer Internet use, and the lowest was again for work-related Internet use. In relation to frequency of use, the highest mean Internet use was for transferring files and the lowest was for e-mailing. (Technically, the highest IAT and IRPS scores were for those who primarily used the Internet for online gaming. However, there was only one participant in this category.)

\section{Factor analysis of the Internet Addiction Test}

Initially, measures of sampling adequacy were carried out on the 20-item IAT to see whether it was suitable for factor analysis. Bartlett's test of sphericity indicated a chi-square value of $2207.8(p<0.0001)$, while a Kaiser-Meyer-Olkin measure of sampling adequacy indicated a value of 0.92 . When a basic scree test and eigenvalue $>1.0$ criteria were used, three factors were generated from the IAT. These three factors, which were rotated to position of maximum orthogonality in six iterations, explained $56.3 \%$ of the variance (see Table 4). Factor 1 (nine items) accounted for $42.7 \%$ of the variance and appeared to measure emotional/psychological conflict (e.g., How often do you prefer the excitement of the Internet to intimacy with your partner? How often do you block disturbing thoughts about your life with soothing thoughts of the Internet? How often do you hide how long you have been online?). Factor 2 (six items) accounted for $8 \%$ of the variance and appeared to measure time management issues (e.g., How often do you find that you stay online longer than you intended? How often do you find yourself saying "Just a few more minutes" when online?). Factor 3 (six items) accounted for $5.6 \%$ of the variance and appeared to measure mood modification (e.g., How often do you fear life without the Internet would be boring, empty, and joyless? How often do you feel depressed, moody, or nervous when you are offline, which goes away once you are back online? How often do you feel preoccupied with the Internet when offline, or fantasize about being online?).

\section{Factor analysis of IRPS}

Initially, measures of sampling adequacy were carried out on the 20-item IRPS to see whether it was suitable for factor analysis. Bartlett's test of sphericity indicated a chi-square value of $2164.3(p<0.0001)$, while a Kaiser-Meyer-Olkin

Table 2. Gender Differences in Correlations Between Age, Duration of Internet Use,

Frequency of Use, Total Internet Addiction Test Scores, Total Internet-Related Problem Scale Scores, AND the SElf-Diagnostic Question $(N=225)$

\begin{tabular}{|c|c|c|c|c|c|c|c|c|c|c|c|c|}
\hline & \multicolumn{2}{|c|}{ Age } & \multicolumn{2}{|c|}{$\begin{array}{l}\text { Duration } \\
\text { of Internet use }\end{array}$} & \multicolumn{2}{|c|}{$\begin{array}{l}\text { Frequency } \\
\text { of Internet use }\end{array}$} & \multicolumn{2}{|c|}{$\begin{array}{c}\text { Total } \\
\text { IAT scores }\end{array}$} & \multicolumn{2}{|c|}{$\begin{array}{c}\text { Total } \\
\text { IRPS scores }\end{array}$} & \multicolumn{2}{|c|}{$\begin{array}{l}\text { Self-diagnostic } \\
\text { question }\end{array}$} \\
\hline & Males & Females & Males & Females & Males & Females & Males & Females & Males & Females & Males & Females \\
\hline Age & 1 & 1 & & & & & & & & & & \\
\hline Duration of Internet use & $0.30^{* *}$ & 0.12 & 1 & 1 & & & & & & & & \\
\hline Frequency of Internet use & 0.20 & 0.10 & 0.20 & 0.19 & 1 & 1 & & & & & & \\
\hline Total IAT scores & -0.23 & -0.09 & -0.21 & 0.11 & 0.06 & $0.33^{* *}$ & 1 & 1 & & & & \\
\hline Total IRPS scores & -0.21 & -0.15 & -0.22 & 0.14 & 0.06 & $0.37^{* *}$ & $0.90^{* *}$ & $0.89^{* *}$ & 1 & 1 & & \\
\hline Self-diagnostic question & $-0.26^{*}$ & 0.01 & 0 & 0.14 & $0.30 *$ & 0.10 & $0.41^{* *}$ & $0.39^{* *}$ & $0.39^{* *}$ & $0.40^{* *}$ & 1 & 1 \\
\hline
\end{tabular}

${ }^{*}$ Correlation is significant at the 0.05 level; ${ }^{* *}$ correlation is significant at the 0.01 level. 
Table 3. Means of Total Internet Addiction Test Scores, Total Internet-Related Problem Scale Scores, Duration of Internet Use, and Frequency of Internet Use Across Different Types of Applications Most Used

\begin{tabular}{|c|c|c|c|c|c|}
\hline & $\begin{array}{l}\text { Total } \\
\text { IAT score }\end{array}$ & $\begin{array}{l}\text { Total } \\
\text { IRPS score }\end{array}$ & $\begin{array}{c}\text { Duration of Internet } \\
\text { use (years) }\end{array}$ & $\begin{array}{c}\text { Frequency of Internet } \\
\text { use (hours/day) }\end{array}$ & $\begin{array}{l}\text { Age } \\
\text { (years) }\end{array}$ \\
\hline Browsing the web $(n=63)$ & 39.0 & 59.8 & 6.1 & 2.9 & 27.2 \\
\hline Specific information searching $(n=27)$ & 36.2 & 58.0 & 5.7 & 2.1 & 28.7 \\
\hline E-mailing $(n=63)$ & 32.6 & 49.1 & 5.9 & 1.4 & 24.6 \\
\hline Using forums $(n=3)$ & 44.7 & 70.3 & 5.5 & 3.5 & 18.7 \\
\hline Online chatting $(n=46)$ & 41.6 & 68.7 & 6.3 & 2.3 & 21.2 \\
\hline Online shopping (incl. auctioning) $(n=6)$ & 37.3 & 64.8 & 6.7 & 2.3 & 29.0 \\
\hline Online gaming $(n=1)$ & 66.0 & 117.0 & 5.0 & 4.0 & 19.0 \\
\hline Work-related online activities $(n=3)$ & 26.7 & 28.7 & 5.7 & 2.0 & 34.0 \\
\hline File transferring $(n=5)$ & 42.6 & 71.6 & 6.6 & 9.5 & 24.6 \\
\hline Other online activities $(n=2)$ & 37.4 & 58.9 & 6.0 & 2.4 & 25.3 \\
\hline
\end{tabular}

measure of sampling adequacy indicated a value of 0.91 . When a basic scree test and eigenvalue $>1.0$ criteria were used, four factors were generated from the IRPS. These four factors, which were rotated to position of maximum orthogonality in five iterations, explained $60.2 \%$ of the variance (see Table 5). Factor 1 (12 items) accounted for $41 \%$ of the variance and appeared to measure the negative effects of Internet use (e.g., My Internet use has replaced some of my usual sleeping hours. I am often late for appointments because I am online when I shouldn't be). Factor 2 (five items) accounted for $7.3 \%$ of the variance and appeared to measure mood modification (e.g., I have used the net to make myself feel better when I was down. I use the net to talk to others when I feel isolated. I have used the net to make myself feel better when I was down). Factor 3 (three items) accounted for $6.3 \%$ of the variance and appeared to measure loss of control (e.g., The amount of information I get from the Internet is never enough. My productivity at work/university has decreased as a direct result of the time I spent on the Internet).

Table 4. Factor Analysis of Internet Addiction Test

\begin{tabular}{|c|c|c|c|c|}
\hline & \multirow[b]{2}{*}{ How often ... } & \multicolumn{3}{|c|}{ Component } \\
\hline & & 1 & 2 & 3 \\
\hline Q3 & do you prefer the excitement of the Internet to intimacy with your partner? & 0.49 & 0.01 & 0.36 \\
\hline Q5 & do others in your life complain to you about the amount of time you spend online? & 0.53 & 0.04 & 0.08 \\
\hline$\widehat{Q} 8$ & does your job performance or productivity suffer because of the Internet? & 0.49 & 0.49 & -0.08 \\
\hline Q9 & do you become defensive or secretive when anyone asks you what you do online? & 0.65 & 0.04 & 0.1 \\
\hline Q10 & do you block disturbing thoughts about your life with soothing thoughts of the Internet? & 0.78 & -0.02 & 0.07 \\
\hline Q11 & do you find yourself anticipating when you will go online again? & 0.4 & 0.18 & 0.37 \\
\hline Q17 & do you try to cut down the amount of time you spend online and fail? & 0.72 & 0.21 & -0.04 \\
\hline Q18 & do you try to hide how long you've been online? & 0.9 & -0.03 & -0.16 \\
\hline Q19 & do you choose to spend more time online over going out with others? & 0.5 & 0.03 & 0.33 \\
\hline Q1 & do you find that you stay online longer than you intended? & -0.05 & 0.71 & 0.13 \\
\hline Q2 & do you neglect household chores to spend more time online? & 0.03 & 0.55 & 0.4 \\
\hline Q6 & $\begin{array}{l}\text { does your work suffer (e.g., postponing things, not meeting deadlines, etc.) because of } \\
\text { the amount of time you spend online? }\end{array}$ & 0.33 & 0.55 & 0.05 \\
\hline Q7 & do you check your e-mail before something else that you need to do? & 0 & 0.76 & -0.12 \\
\hline Q16 & do you find yourself saying "Just a few more minutes" when online? & 0.17 & 0.5 & 0.29 \\
\hline Q4 & do you form new relationships with fellow online users? & -0.03 & -0.02 & 0.67 \\
\hline Q12 & do you fear that life without the Internet would be boring, empty, and joyless? & 0.08 & -0.01 & 0.76 \\
\hline Q13 & do you snap, yell, or act annoyed if someone bothers you while you are online? & 0.05 & 0.12 & 0.63 \\
\hline Q14 & do you lose sleep due to late-night log-ins? & -0.05 & 0.32 & 0.6 \\
\hline Q15 & do you feel preoccupied with the Internet when off-line, or fantasize about being online? & 0.4 & -0.05 & 0.47 \\
\hline \multirow[t]{9}{*}{ Q20 } & $\begin{array}{l}\text { do you feel depressed, moody, or nervous when you are off-line, which goes away once } \\
\text { you are back online? }\end{array}$ & 0.44 & -0.24 & 0.49 \\
\hline & Eigenvalue & 8.53 & 1.59 & 1.12 \\
\hline & $\%$ of variance explained & 42.67 & 7.97 & 5.61 \\
\hline & Extraction method: Principal component analysis & & & \\
\hline & Rotation method: Oblimin with Kaiser Normalization & & & \\
\hline & a. Rotation converged in 11 iterations & & & \\
\hline & F1-psychological/emotional conflict & & & \\
\hline & F2-time-management problems & & & \\
\hline & F3-mood modification & & & \\
\hline
\end{tabular}

Bold values indicate components that each individual question loaded on most heavily. 
Table 5. Factor Analysis of the Internet-Related Problem Scale

\begin{tabular}{|c|c|c|c|c|c|}
\hline & & \multicolumn{4}{|c|}{ Component } \\
\hline & & 1 & 2 & 3 & 4 \\
\hline Q3 & $\begin{array}{l}\text { I have given up some of my social and leisure time so I can spend more time on } \\
\text { the net. }\end{array}$ & 0.34 & -0.17 & 0.21 & -0.34 \\
\hline Q5 & I have tried unsuccessfully to cut down my amount of Internet use. & 0.73 & 0.13 & -0.13 & -0.06 \\
\hline Q6 & $\begin{array}{l}\text { When not online, I spend a lot of time doing other things related to the Internet } \\
\text { (e.g. buying and reading Internet magazine and books, reorganizing files of } \\
\text { downloaded materials, trying out new WWW browsers). }\end{array}$ & 0.76 & -0.24 & -0.08 & 0.11 \\
\hline Q7 & I have received phone bills I couldn't afford to pay. & 0.38 & -0.28 & -0.09 & -0.33 \\
\hline Q11 & I have tried to stop using the Internet for prolonged periods. & 0.59 & -0.25 & 0.06 & -0.13 \\
\hline Q12 & My Internet use has replaced some of my usual sleeping hours. & 0.71 & -0.01 & 0.27 & 0.01 \\
\hline Q15 & My friends and family complain about my use of the Internet. & 0.65 & -0.14 & 0.07 & -0.09 \\
\hline Q17 & I find myself connecting for longer periods than intended. & 0.54 & 0.01 & -0.14 & -0.04 \\
\hline Q19 & I am often late for appointments because I am online when I shouldn't be. & 0.74 & 0.16 & 0.21 & 0.05 \\
\hline Q20 & I am the kind of person who feels more comfortable with objects than people. & 0.46 & -0.31 & -0.01 & 0.03 \\
\hline Q13 & $\begin{array}{l}\text { I feel anxious if I have not read my email or connected to the Internet } \\
\text { for sometime. }\end{array}$ & 0.44 & -0.46 & -0.27 & -0.01 \\
\hline Q2 & I have used the net to make myself feel better when I was down. & -0 & -0.81 & 0.19 & 0.17 \\
\hline Q10 & I have used the net to talk to others when I was feeling isolated. & -0.1 & -0.88 & 0.12 & -0.06 \\
\hline Q14 & I have frequent dreams about the Internet. & 0.09 & -0.62 & -0.09 & -0.3 \\
\hline Q18 & $\begin{array}{l}\text { There are times when I would rather use the net than deal with other pressing } \\
\text { issues. }\end{array}$ & 0.14 & -0.63 & -0.19 & -0.06 \\
\hline Q4 & When not connected, I find myself wondering what is happening on the Internet. & 0.39 & -0.19 & 0.4 & -0.36 \\
\hline Q1 & The amount of information I get from the Internet is never enough. & -0 & -0.05 & 0.8 & 0.05 \\
\hline Q16 & $\begin{array}{l}\text { My productivity at work (or school) has decreased as a direct result of the time } \\
\text { I spent on the Internet. }\end{array}$ & 0.32 & -0.07 & 0.39 & -0.28 \\
\hline Q8 & $\begin{array}{l}\text { When I haven't been able to connect for some time, I become preoccupied with the } \\
\text { thought of connecting. }\end{array}$ & 0 & -0.43 & 0.11 & -0.55 \\
\hline Q9 & $\begin{array}{l}\text { The time I spend online has increased over the last } 12 \text { months. } \\
\text { Eigenvalue } \\
\% \text { of Variance explained }\end{array}$ & $\begin{array}{r}-0.1 \\
8.2 \\
41\end{array}$ & $\begin{array}{l}0.14 \\
1.47 \\
7.33\end{array}$ & $\begin{array}{r}-0.06 \\
1.27 \\
6.33\end{array}$ & $\begin{array}{r}-0.92 \\
1.11 \\
5.57\end{array}$ \\
\hline & Extraction method: Principal Component Analysis & & & & \\
\hline & Rotation method: Oblimin with Kaiser Normalization & & & & \\
\hline & a. Rotation converged in eight iterations & & & & \\
\hline & F1-negative effects & & & & \\
\hline & F2-mood modification & & & & \\
\hline & F3-loss of control & & & & \\
\hline & F4-increased use & & & & \\
\hline
\end{tabular}

Bold values indicate components that each individual question loaded on most heavily.

Factor 4 (three items) accounted for $5.6 \%$ of the variance and appeared to measure increased Internet use (e.g., The time I spend online has increased over the past 12 months).

\section{The self-diagnostic question}

Of the 225 participants, 25 of them (11\%) defined themselves as Internet addicts. The self-defined Internet addicts comprised nine males (13\% of all males) and 16 females (10.3\% of all females). A significant difference was found between the self-defined addicts and the non-addicts in their total IAT scores $(t=7.28, d f=28.96 ; p<0.01)$ and IRPS scores $(t=7.14, d f=28.51 ; p<0.01)$.

\section{Correlations between the Internet Addiction Test, Internet-Related Problem Scale, and the self-diagnostic question}

The scores of the three different Internet addiction measures were strongly correlated to each other (see Table 6), especially the total IAT and IRPS scores $(r=0.90 ; p<0.01)$. The self-diagnostic question was found to be significantly correlated to both total IAT score $(r=-0.4 ; p<0.01)$ and IRPS score $(r=0.4 ; p<0.01)$. The highest correlation between the factors was found between Factor 1 (tolerance and conflict) of the IAT and Factor 1 (negative effects) of the IRPS ( $r=0.86$; $p<0.01$ ), while the lowest was between Factor 2 (timemanagement issues) of the IAT and Factor 4 (increased use) of the IRPS $(r=0.47 ; p<0.01)$. In relation to the self-diagnostic question, all the correlations with the IAT and IRPS factors and total scores were found to be significant (see Table 6).

\section{Correlations between age, duration of Internet use, frequency of Internet use, Internet Addiction Test factors, Internet-Related Problem Scale factors, and the self-diagnostic question}

Age was found to be significantly correlated to IAT Factor 3 (time-management issues, $r=-0.18 ; p<0.01$ ) and IRPS Factor 3 (loss of control, $r=-0.22 ; p<0.01$ ). Duration of Internet use was not found to be significantly correlated with any of the IAT or IRPS factors. Frequency of Internet use was found to be significantly correlated with IAT Factor 2 
Table 6. Correlations between the Internet Addiction Test and Internet-Related Problem Scale Factors, and the Self-Diagnostic Question

\begin{tabular}{|c|c|c|c|c|c|c|c|c|c|c|}
\hline & $\begin{array}{c}\text { IAT } \\
\text { Factor } 1\end{array}$ & $\begin{array}{c}I A T \\
\text { Factor } 2\end{array}$ & $\begin{array}{c}I A T \\
\text { Factor } 3\end{array}$ & $\begin{array}{c}\text { IRPS } \\
\text { Factor } 1\end{array}$ & $\begin{array}{c}\text { IRPS } \\
\text { Factor } 2\end{array}$ & $\begin{array}{c}\text { IRPS } \\
\text { Factor } 3\end{array}$ & $\begin{array}{c}\text { IRPS } \\
\text { Factor } 4\end{array}$ & $\begin{array}{l}\text { Total } \\
\text { IAT }\end{array}$ & $\begin{array}{l}\text { Total } \\
\text { IRPS }\end{array}$ & $\begin{array}{l}\text { Self-diagnostic } \\
\text { question }\end{array}$ \\
\hline IAT Factor 1 & 1 & & & & & & & & & \\
\hline IAT Factor 2 & $0.71^{* *}$ & 1 & & & & & & & & \\
\hline IAT Factor 3 & $0.74^{* *}$ & $0.60^{* *}$ & 1 & & & & & & & \\
\hline IRPS Factor 1 & $0.86^{* *}$ & $0.68^{* *}$ & $0.80^{* *}$ & 1 & & & & & & \\
\hline IRPS Factor 2 & $0.63^{* *}$ & $0.61^{* *}$ & $0.68^{* *}$ & $0.71^{* *}$ & 1 & & & & & \\
\hline IRPS Factor 3 & $0.66^{* *}$ & $0.51^{* *}$ & $0.46^{* *}$ & $0.63^{* *}$ & $0.45^{* *}$ & 1 & & & & \\
\hline IRPS Factor 4 & $0.66^{* *}$ & $0.78^{* *}$ & $0.54^{* *}$ & $0.7^{* *}$ & $0.56^{* *}$ & $0.54^{* *}$ & 1 & & & \\
\hline Total IAT & $0.93^{* *}$ & $0.86^{* *}$ & $0.86^{* *}$ & $0.88^{* *}$ & $0.71^{* *}$ & $0.63^{* *}$ & $0.74^{* *}$ & 1 & & \\
\hline Total IRPS & $0.84^{* *}$ & $0.75^{* *}$ & $0.79 * *$ & $0.94^{* *}$ & $0.86^{* *}$ & $0.70^{* *}$ & $0.78^{* *}$ & $0.90^{* *}$ & 1 & \\
\hline Self-diagnostic question & $0.34^{* *}$ & $0.34^{* *}$ & $0.41^{* *}$ & $0.41^{* *}$ & $0.33^{* *}$ & $0.19^{* *}$ & $0.30^{* *}$ & $0.40^{* *}$ & $0.40^{* *}$ & 1 \\
\hline
\end{tabular}

${ }^{*}$ Correlation is significant at the 0.05 level; ${ }^{* *}$ correlation is significant at the 0.01 level.

(time-management issues, $r=0.26, p<0.01$ ), IAT Factor 3 (mood modification, $r=0.18 ; p<0.05$ ), IRPS Factor 1 (negative effects, $r=0.20 ; p<0.05)$, IRPS Factor 2 (mood modification, $r=0.21 ; p<0.01$ ), and IRPS F3 (loss of control, $r=0.22$; $p<0.01)$. All these results are summarized in Table 7 .

\section{Discussion}

The aim of this study was to explore in depth the psychometric properties of two measures of Internet Addictionthe Internet Addiction Test ${ }^{9}$ and the Internet-Related Problem Scale ${ }^{10}$-and their relationship with a simple self-diagnostic question. ${ }^{13}$ In contrast to previous research findings that reported more problems in more recent users due to their Internet use, ${ }^{14,15}$ the results of this study seemed to suggest that there was no association. No relationship was found between age and total IAT and IRPS scores either, which is inconsistent with previous findings that have reported younger users experiencing more problems compared to older users. ${ }^{13,16-18}$

An association between age and duration of use was found in male participants but not in female participants. This may have been because the males in this study were significantly older than the females, and therefore have lived more years in

Table 7. Correlations Between Age, Duration of INTERNET UsE, FREQUENCY OF INTERNET UsE, INTERNET Addiction Test Factors, Internet-Related Problem Scale Factors, and the Self-Diagnostic Question

\begin{tabular}{llcc}
\hline & Age & $\begin{array}{c}\text { Duration of } \\
\text { Internet use }\end{array}$ & $\begin{array}{c}\text { Frequency of } \\
\text { Internet use }\end{array}$ \\
\hline IAT Factor 1 & -0.06 & -0.03 & 0.13 \\
IAT Factor 2 & -0.04 & 0.08 & $0.26^{* *}$ \\
IAT Factor 3 & $-0.18^{* *}$ & 0.02 & $0.18^{*}$ \\
IRPS Factor 1 & -0.12 & 0.02 & $0.20^{*}$ \\
IRPS Factor 2 & -0.10 & 0.09 & $0.21^{* *}$ \\
IRPS Factor 3 & $-0.22^{* *}$ & -0.01 & $0.22^{* *}$ \\
IRPS Factor 4 & -0.10 & -0.03 & 0.06 \\
Self-diagnostic & -0.08 & -0.04 & 0.11 \\
$\quad$ question & & & \\
\hline
\end{tabular}

${ }^{*}$ Correlation significant at the 0.05 level; ${ }^{* *}$ correlation significant at the 0.01 level. the contemporary Internet age and are likely to have encountered the Internet before the female sample. Age was found to be associated with most of the variables. Older Internet users had been (predictably) online longer, but also spent more time online. No association was found between age and total IAT and IRPS scores, suggesting that age is not a factor in problematic Internet use.

Participants' frequency of use also had a positive correlation to their total IAT and IRPS scores, suggesting that participants who spent more time online were more likely to have problematic Internet usage. However, further analyses showed a correlation between frequency of use and total IAT and IRPS scores in female participants but not for males. This suggests that excessive use of the Internet by males does not lead to problems, whereas in females it does. However, in terms of the IAT and IRPS, males had significantly higher scores than females. This suggests that for males, whilst Internet use is more problematic, it is not necessarily related to the time they spend online.

Some researchers have questioned the nature of Internet addiction. For instance, Griffiths ${ }^{19}$ has argued that most of the individuals who use the Internet excessively are not addicted to the Internet itself but use it as a medium to fuel other addictions. He gave the examples of a gambling addict who chooses to engage in online gambling, and online computer gaming addicts who play online, stressing that the Internet is just the place where they conduct their chosen addictive/ excessive behavior. In contrast, he also acknowledged that there are some case studies that seem to suggest an addiction to the Internet itself. ${ }^{20,21}$ Most of these individuals use functions of the Internet that are not available in any other medium, such as chat rooms or various role-playing games. Therefore, one of the items in the questionnaire asked participants to state the one Internet application that they use the most.

This was included in order to explore if users of the different types of application would also differ in their Internet addiction scores (i.e., to ascertain if particular applications are more addictive than others). The top three most used applications in this study were web browsing, e-mailing, and online chatting. However, the practicality and validity of asking participants to pick just one Internet application that they most often use can be questioned. First, most Internet users utilize more than one online application. It is increasingly 
unlikely for users to use the Internet simply to access their email or to web browse only. It may have therefore been difficult for Internet users to pick one single application that they use the most or spend most of their online time on. Furthermore, some of the categories of use were interconnected. For example, some examples of using the Internet for "work purposes" could also have been classed as "specific information search." The only reliable way of actually measuring participants' usage of different applications accurately is to get them to record their average usage of different applications in 1 week.

Despite the difficulty in getting an accurate account of what participants' usages are of different types of application, this is one factor that is worth exploring further. Although the users of various different functions were unevenly spread in this study (see Table 3), some variations were found in the mean frequency of use, age, and total IAT and IRPS scores. This at least suggests that users from different functions differ in terms of how long they spend online and what level of problems they have due to their Internet use. Excluding online gaming, which only had one participant, the Internet applications that had the highest mean scores were Internet forums (IAT) and file transferring (IRPS). What these disparities in the IAT and IRPS scores, as well as the mean frequency of use across the different functions, might imply is that each function may have a different pattern of usage and a different type of user. Instead of looking at Internet use in general, it would be more useful to research according to specific functions.

In order to explore the psychometric properties of the IAT, factor analysis was performed on the IAT scores, and three factors were extracted from the 20-item questionnaire. These were psychological/emotional conflict (Factor 1), salience (Factor 2), and time-management issues (Factor 3). These scales showed good internal consistency. The first factor (IAT F1) explained most of the variance $(42.7 \%)$. It was also found to be the most reliable, as indicated by the highest Cronbach's alpha. This factor appeared to highlight the psychological/ emotional conflict component, as it contained items relating to a preference to being online at the cost of their social lives, and sacrificing their time with friends/family to be online. Items in this factor also included others complaining about the person's Internet use, choosing to go online over going out with others, and being secretive or defensive when asked about how much time they spent online.

The second factor (IAT F2) contained six factors that clearly seemed to tap into time-management issues. This scale had a high Cronbach's alpha and accounted for $8 \%$ of the variance. Items included in this scale asked if participants spend more time online than they had originally intended, if they checked their e-mails before anything else they needed to do, and if their productivity suffering due to the time they spend online. A negative correlation was found between this factor and age, suggesting that younger users seem to have more problems with managing their online time compared to older users. Items with high loadings on this factor included "neglecting household chores" and "decreased productivity." This is consistent with previous findings ${ }^{20}$ that reported younger users having more problems with their Internet use, particularly in relation to neglecting work. A positive correlation was also found between IAT F2 and participants' average use, which signified that participants with higher average use would have higher scores on this time-management issues scale. All the factors were significantly correlated with each other and to all the IRPS factors and the self-diagnostic question.

The third factor (IAT F3) appeared to highlight salience in terms of the mood modification element. This scale also shows high reliability, considering its Cronbach's alpha. The item that had the highest loading on this factor asked if participants fear that life without the Internet would be empty, boring, and joyless. Other items with high loadings on this factor asked if they get upset when someone bothered them while they were online; feel depressed, moody, or nervous when they are offline; and lose sleep due to late online sessions. This factor was found to be correlated with participants' average Internet use, which implies that those who spend more time online would have a higher score on this scale. Although no cause and effect could be attributed, it would follow the logical reasoning that participants who use the Internet to relax or modify their moods in any way would spend more time online.

The factors extracted from the 20-item IRPS were not as easily or clearly defined as those of the IAT, in that each factor seemed to highlight several different components simultaneously. For example, the items in the first factor appeared to contain items that measured salience, negative effects, and conflict. The second factor appeared to be related to both salience and mood modification. Factors 3 and 4 were difficult to label accurately, as the high loading factors did not seem to have a coherent underlying theme. On closer examination, IRPS F1 appeared to be about over-involvement of Internet use and included spending a lot of time doing other things related to the Internet when they were not online, the Internet replacing some sleeping hours, and being unable to cut down the amount of Internet use. This factor accounted for $41 \%$ of the variance, and had a high Cronbach's alpha (0.9). The second factor, IRPS F2, appeared to highlight the importance of the Internet for mood modification. The items included in this factor included using the Internet to feel better, being preoccupied with connecting after being offline for a while, having frequent dreams about the Internet, and preferring to be online rather than dealing with other more pressing issues. This factor also had a high Cronbach's alpha (0.86), compared to IRPS F3 (0.64) and IRPS F4 (0.60).

It should be noted that items in both IRPS F3 (I have given up some of my social and leisure time so I can spend more time on the net; When I haven't been able to connect for sometime, I become preoccupied with the thought of connecting; The amount of time I spend online has increased over the last 12 months) and IRPS F4 (When not connected, I find myself wondering what's happening on the Internet; My productivity at work/school has decreased as a direct result of the time I spend online; The information I get from the Internet is never enough) did not seem to fit together logically although these two factors were labeled as loss of control (IPRS F3) and increased Internet use (IRPS F4). The item with the highest loading (0.86) on the IRPS F3 seemed to tap into tolerance (The amount of time I spend online has increased over the last 12 months), while the other two items seem to tap into salience.

Upon further scrutiny of the items in each of the Internet addiction measures, some particular questions appear to need revising. For example, Question 7 on the IRPS asked if participants had ever received a phone bill they could not afford 
to pay. For most participants, this question did not really apply because of the (now) low cost of broadband and/or free access via a third party (e.g., university). Item 1 of the IRPS (The information I get from the Internet is never enough) is supposed to tap into tolerance and Item 20 (I am the kind of person who feels more comfortable with objects than people) is supposed to measure introversion. However, participants in this study said these items were ambiguous. In relation to the IAT, item 4 asks participants how often they form new relationships with fellow online users. While this may have been uncommon when the measure was developed, it is now the norm for most young people via social networking and online dating sites.

Analysis of the self-diagnostic question ${ }^{13}$ revealed significant associations with both total IAT and IRPS scores, implying that participants who defined themselves as "Internet addicts" have higher scores on the two measures $(11 \%$ of the 225 participants). The is a finding of particular interest, as it would seem that participants are fairly accurate at evaluating their own level of problems with the Internet, although further research would need to confirm this.

As with many previous studies conducted online, this study suffered from a number of limitations. This was a nonrandom voluntary self-selected sample of participants. ${ }^{23}$ However, several studies that have compared Internet and non-Internet samples ${ }^{24,25}$ have found that participants recruited online tend to be more diverse demographically (e.g., in terms of age, ethnicity, geographical locations, etc.). Traditional sampling methods are also often biased (e.g., toward using undergraduate psychology volunteers). If nothing else, with careful planning, design, and appropriate sampling procedures, Internet-mediated research has the potential to access a wider range of participants. This study suffers from the participant recruitment method. Participants for this study were recruited from those already in the research team's database. Furthermore, the number of participants for this study is modest particularly for a study that employed factor analysis as a method. Finally, the data are self-reported and open to many confounding factors including social desirability, reliance on long-term memory, and so on.

As Griffiths ${ }^{19}$ observed, there have been some key problems with the addiction criteria that have been used in most previous studies. He claims many of the instruments used have no measure of severity, no temporal dimension, have a tendency to over-estimate the incidence of the problems, and do not consider the context of Internet use. In terms of the instruments tested in this study, the last point is the most valid one. The instruments did have some measure of severity, as the participants were asked to rate their responses on a Likert scale instead of a simple "yes" or "no." However, it is important for future studies to take into account the context of Internet use and to differentiate between various applications. $^{26}$

\section{Disclosure Statement}

No competing financial interests exist.

\section{References}

1. Shapira N, Lessig M, Goldsmith T, et al. Problematic Internet use: Proposed classification and diagnostic criteria. Depression \& Anxiety 2003; 17:207-16.
2. Beard K. Internet addiction: A review of current assessment techniques and potential assessment questions. CyberPsychology \& Behavior 2005; 8:7-14.

3. Beard K, Wolf E. Modification in the proposed diagnostic criteria for Internet addiction. CyberPsychology \& Behavior 2001; 4:377-83.

4. Pallanti S, Bernardi S, Quercioli L. The Shorter PROMIS Questionnaire and the Internet Addiction Scale in the assessment of multiple addictions in a high-school population: Prevalence and related disability. CNS Spectrums 2006; 11:966-74.

5. Pratarelli M, Browne B. Confirmatory factor analysis of Internet use and addiction. CyberPsychology \& Behavior 2002; 5:53-64.

6. Rotunda RJ, Kass SJ, Sutton MA, et al. Internet use and misuse: Preliminary findings from a new assessment instrument. Behavior Modification 2003; 27:484-504.

7. Nichols LA, Nicki R. Development of a psychometrically sound Internet addiction scale: A preliminary step. Psychology of Addictive Behaviors 2004; 18:381-4.

8. Meerkerk G-J, Van Den Eijnden JJM, Vermulst AA, et al. The Compulsive Internet Use Scale (CIUS): Some psychometric properties. CyberPsychology \& Behavior 2009; 12:1-6.

9. Young K. (1998). Caught in the net. New York: John Wiley.

10. Armstrong L, Phillips JG, Saling LL. Potential determinants of heavier Internet usage. International Journal of HumanComputer Studies 2000; 53:537-50.

11. Kesici S, Sahin I. A comparative study of uses of the Internet among college students with and without Internet addiction. Psychological Reports 2009; 105:1103-12.

12. Kesici S, Sahin I. Turkish adaptation study of Internet Addiction Scale. CyberPsychology, Behavior, \& Social Networking 2010; 13:185-9.

13. Petrie H, Gunn D. (1998) Internet "addiction": The effects of sex, age, depression and introversion. Paper presented at the British Psychological Society Conference, London.

14. Young, K. Internet addiction: The emergence of a new clinical disorder. CyberPsychology \& Behavior 1996; 3:237-44.

15. Mathy $\mathrm{R}$, Cooper $\mathrm{A}$. The duration and frequency of Internet use in a nonclinical sample: Suicidality, behavioural problems, and treatment histories. Psychotherapy: Theory, Research, Practice, Training 2003; 40:125-35.

16. Brenner V. Psychology of Computer Use: XLVII. Parameters of Internet use, abuse, and addiction: The first 90 days of the Internet Usage Survey. Psychological Reports 1997; 80:879-82.

17. Kraut R, Patterson M, Landmark V, et al. Internet paradox: A social technology that reduces social involvement and psychological well being? American Psychologist 1998; 53:1017-31.

18. Wästlund $\mathrm{E}$, Norlander $\mathrm{T}$, Archer T. Internet blues revisited: Replication and extension for an Internet paradox study. CyberPsychology \& Behavior 2001; 4:385-91.

19. Griffiths MD. Internet addiction-Time to be taken seriously? Addiction Research 2000; 8:413-18.

20. Young K. Psychology of computer use: XL. Addictive use of the Internet: A case that breaks the stereotype. Psychological Reports 1996; 79:899-902.

21. Griffiths MD. Does Internet and computer "addiction" exist? Some case study evidence. CyberPsychology \& Behavior 2000; 3: 211-18.

22. Widyanto L, McMurran M. The psychometric properties of the Internet Addiction Test. CyberPsychology \& Behavior 2004; 7:443-50.

23. Azar B. Online experiments: Ethically fair or foul? Monitor on Psychology 2000; 3:50-2. 
24. Smith M, Leigh B. Virtual subjects: Using the Internet as an alternative source of subjects and research environment. Behaviour, Research Methods, Instruments \& Computers 1997; 29:496-505.

25. Krantz J, Ballard J, Scherr J. Comparing the results of laboratory and World Wide Web samples of the determinants of female attractiveness. Behaviour Research Methods, Instruments \& Computers 1997; 29:264-8.

26. Griffiths MD. The role of context in online gaming excess and addiction: Some case study evidence. International Journal of Mental Health \& Addiction 2010; 8:119-25.
Address correspondence to: Mark D. Griffiths, Ph.D. International Gaming Research Unit Psychology Division Nottingham Trent University

Burton Street Nottingham NG1 $4 B U$

UK

E-mail: mark.griffiths@ntu.ac.uk 
